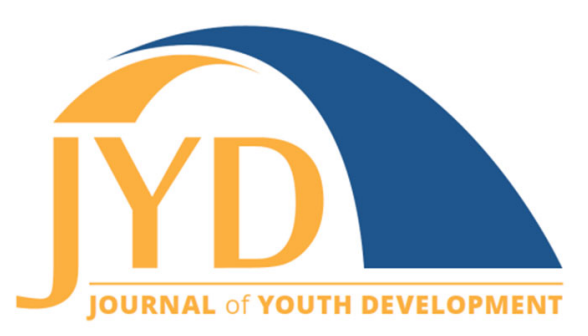

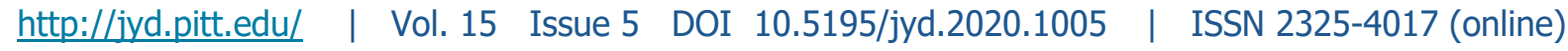

\title{
Race, Antiracism, and Youth Development: From Awareness to Sustained Action
}

\author{
Corliss Wilson Outley \\ Clemson University \\ coutley@clemson.edu \\ Dale A. Blyth \\ University of Minnesota \\ blyth004@umn.edu
}

\begin{abstract}
After yet more vivid examples of how Black people are far too often treated unjustly in America and the enormous response worldwide, it is high time to recognize racism in our field and promote a strong and sustained commitment to antiracist approaches to research, publishing, practice, and policy in the youth development field. This essay begins to make the case for such efforts and calls for sustained action in many areas. These are things we can and must do as a field that supports the positive development of all youth.
\end{abstract}

Key words: racism, antiracist, equity, youth, inclusion

\section{Introduction}

8:46. 8 minutes and 46 seconds. This time has become a symbol of justice and led to protests and performative acts of racial reckoning in the United States and around the globe.

George Floyd was an unarmed Black man publicly killed on the street while in police custody. Breonna Taylor was an unarmed Black woman shot eight times and killed in her own home by police. Ahmaud Arbery was an unarmed Black man who was jogging when he was chased, confronted, shot, and killed by two White men with a shotgun. Each of these are the newest cases that are a part of a long legacy of society devaluing the lives of Black men, women and children. We unequivocally declare and affirm that Black Lives Matter. Black lives not only

(cc) EY New articles in this journal are licensed under a Creative Commons Attribution 4.0 License. This journal is published by the University Library System, University of Pittsburgh and is cosponsored by the University of Pittsburgh Press. The Journal of Youth Development is the official peer-reviewed publication of the National Association of Extension 4-H Youth Development Professionals and the National AfterSchool Association. 


\section{Race, Antiracism, and Youth Development}

matter in our communities, in our states, in our nation and in the world-but they also matter critically in our field. They matter in our colleges and universities; they matter in the leadership and workforce of youth development organizations and programs; and critically, the Black lives of the children and youth who are touched, or too often left untouched, by positive youth development opportunities matter.

The Journal of Youth Development (JYD) is "dedicated to advancing youth development practice and research. JYD serves applied researchers and evaluators as well as practitioners who work in youth-serving organizations or the intermediaries that support them." At the core of this vision is our commitment to valuing and appreciating the diversity of youth, youth workers, and researchers that are dedicated to youth development approaches and positive outcomes for all youth. However, we must recognize that the field of youth development lacks diversity in far too many key areas, with Black people and people of African descent being particularly underrepresented among our research scholars. As a journal and a representative of our larger field, we must condemn racism in all of its many forms and acknowledge the impact that historic, deeply rooted, and systemic inequities have on our youth, our youth workers, and our scholars as well as our institutions and organizations. These current realities are a reflection of centuries of inequity due to discrimination and racism inflicted upon Black communities and actively promoted and too easily tolerated by dominant White society. We acknowledge that such inequities and racism have impacted the field of youth development in ways that may have caused us to be dismissive or remain silent about racism. We must do more than just acknowledge and seek to build awareness of this reality. The time has come to work actively to address inequities and racism not only as a journal but also proactively in our larger field. We cannot remain silent in the face of these injustices because it will serve only to perpetuate racism which contradicts our mission to better the lives of all youth.

JYD believes we must promote equity, inclusion, accessibility, and diversity at all levels, and find ways to not only encourage participation but richly engage individuals of all racial and ethnic backgrounds. In addition, we must examine how privilege manifests in our daily lives and our work-from examining our own tendencies to stereotype Black youth to actively calling out racist or exclusionary policies and practices; from reconsidering models and frameworks that put Black youth at a disadvantage to developing new action and support for all Black youth and others who experience hatred and discrimination. 
Race, Antiracism, and Youth Development

\section{Confronting Historical Racism Within the Field}

Racism is an insidious social determinant that systemically dehumanizes the lives of Black people in America. Within the youth development field, persistent racial inequities contribute to disparity in educational opportunities, physical health, psychological well-being, healthcare access, housing availability, life quality, and ultimately, survival. The youth development field, like so many others, must use this moment to address inequities due to historical racism and various forms of ongoing bias and discrimination. Racism and other structural barriers to opportunity have created underlying social, economic, and health conditions that have left youth of color, especially Black youth, facing disproportionate and unfair risks and in some cases death.

In the United States race is a social construct that is designed to stratify people based on social categories while simultaneously establishing meaning within sociopolitical contexts. As a result, race is entangled within political, social, and cultural structures, policies, actions, and beliefs that systematize and uphold unequal distribution of privilege, power, and resources by favoring the dominant White racial group. Thus, racism serves as a tool to dehumanize the nondominant racial group, particularly Black Americans, through prejudice, stereotypes, institutional and structural racism, and discrimination. While many Whites may not see themselves as privileged, all have the very real privilege of not being arbitrarily and unfairly judged every day by the color of their skin-and that privilege makes a difference, sometimes a fatal difference.

\section{Racism as a Construct in Youth Development}

The concepts, frameworks, models, and theories central to the youth development field, especially in regard to Black youth, has led to the development of approaches that essentially focus on racial difference and ultimately too often lay responsibility on the oppressed. This oppression has been normalized by focusing on developmental approaches that emphasize individual differences as a result of ability, motivation, and ambition, while simultaneously deemphasizing the importance of historical colonialization and the historical development of structural inequalities within communities and society (Ginwright \& Cammarota, 2002 ; AdamsWiggins \& Taylor-García, 2020). The overall structure that sustains this inequality allows whiteness to be unburdened by its role through the continual use of neutral and universal standards which can be seen in the discourse, theories, and approaches utilized within our field. For example, this normalization is reflected in the social construction of "at-risk" and "underrepresented," common discourses that have historically been misused to justify what 
Journal of Youth Development | http://jyd.pitt.edu/ | Vol. 15 Issue 5 DOI 10.5195/jyd.2020.1005

Race, Antiracism, and Youth Development

constitutes normative development in comparison to "alleged" deviance among Black youth (Unger 2004).

The social construction of these terms has been grounded within risk and prevention discourse by politicizing from a position of power and privilege that certain youth are problematic without acknowledging that their status is being produced due to oppressive conditions. Deschenes, McLaughlin, and Newman (2008) further acknowledge that the risk discourse has permeated the policy sector in that it has led to increased funding for community youth organizations that emphasize social problems in order to obtain resources and support. Unfortunately, this discourse has led to the justification of increased surveillance of youth, implementation of policies, laws and practices that limit youth agency and voice, and increased regulation of youth behavior within society (Gabriel, et al, 2020). This is further illustrated in recent critiques of developmental approaches surrounding "resilience" and "grit" (Foster \& Spencer, 2011; Gale \& Bolzan, 2013; Unger, 2004) that have renewed previous concerns that they reflect a history within the field that has continually focused on a youth's ability to negotiate challenging circumstances without acknowledging social inequality that gives rise to and exacerbates these developmental challenges-challenges that are grounded in the sociopolitical environment in which they live. Bottrel (2009) further critiques these notions by asserting that the fields can only understand the development of youth by allowing them to define what they determine as positive outcomes in their own voice and context. For example, a recent special issue of Child Development recognized the value of analyzing the social inequalities within the field by acknowledging the historical work of Spencer's (2006) phenomenological variant of ecological systems theory (PVEST) and García Coll et al.'s (1996) integrative model. Both models have provided an ecological view that provides a focus on the contexts that are "specific to those occupying stigmatized social positions instead of inappropriately assuming the experiences of those in dominant social positions are universal" (Adams-Wiggins \& Taylor-Garcia, 2020, p. 488). Additional work in the field (Ginwright \& Cammarota, 2002; Marks et al., 2015; Weiland \& Yoshikawa, 2012) have also emphasized the role of continued inequality and its effect on the lives of youth. However, Killen et al. (2016) suggest that additional work is still needed to move the field forward.

The youth development field has begun to change the discourse around marginalized youth but still continues to diminish the role social, political and economic forces and their related systems, structures and institutions have had on developmental outcomes. As a result, the youth development field must not only work to change the lives of youth, but also engage in 


\section{Race, Antiracism, and Youth Development}

changing the institutional, systemic, and cultural practices that prevent equal access and opportunity for youth throughout society. Based on Ginwright and Cammarota's (2002) foundational work on theorizing the social justice youth development (SJYD) model, Outley et al. (2018) suggest a positive youth development approach that focuses on "the development of equitable access and opportunities for all youth by actively reducing or eliminating disparities in education, health, employment, justice, and any other system that hinders the development of young people" (p. 486). A focus on inequalities brings to light the deficit and cultural pathological colonial views that have kept Black youth and the communities they live in powerless (Pinckney et al., 2018). This type of strategy ensures that the development of youth is not only transformative but refocuses on the systemic inequalities and the lived experience through a broader sociopolitical systemic lens along with their connected histories (Cammarota \& Fine, 2010; Gabriel et al., 2020; Kirshner \& Ginwright, 2012; Outley et al., 2018).

JYD affirms that in order to fulfill our belief that each child and youth has the potential to develop into a productive adult we must begin to acknowledge the injustices done to Black youth including, but not limited to, the ways we study, portray and misrepresent their lives. The field-researchers, academics, practitioners and policymakers - can actively serve as interlocutors and seek to understand not only the history of the field but ensure that our research, programs and services, and policies align with our values. It is only with this acknowledgement and focus on the health and well-being of all youth that we can guarantee all of our futures-and ensure our field is a positive force to these ends.

\section{Call to Action to Address the Impact of Racism on the Field}

Given all of these impacts, we must also acknowledge that these inequalities play out within the halls of academia, youth development settings and programs, and the policies and processes within them. We cannot move forward as a field if we remain silent in the face of an issue that so profoundly impacts so many of our Black youth in particular and many more Indigenous youth, youth of color, and immigrants. The youth development field cannot promote youth development or enhance the careers of our youth workers or even develop new theoretical frameworks if we ignore the pervasive inequities that are often insurmountable barriers to the developmental growth of Black youth. In the face of these historic and systemic issues, it is not enough just to seek not to be a racist area of inquiry and practice. The field of youth development and its leaders, especially White cisgender males who have built their careers in this area, must speak out against racism in the field and serve as allies in order to ensure 
change. To achieve this, we must strive to become an antiracist field. We must recognize that the power of racism as a structuring ideology within society lies in its ability to reimagine itself in new moments and contexts; as a result, in this historic moment, we must resolve to pursue bold action beyond rhetoric and performance by standing with the communities we study and serve to eliminate inequities.

To proactively help us accomplish this, we believe JYD must become dedicated to leading the field with a responsive and resilient approach to establishing and sustaining a variety of concrete antiracist approaches in order to obtain systemic change for the field. We want to introduce a reframed youth development agenda that not only recognizes the connection between structural racism and racialized disparities in youth developmental outcomes, but also utilizes a system-wide, multipronged, multilevel, and interdisciplinary approach. The youth development field is uniquely positioned to facilitate these broad approaches, as limited as they are, by playing a major role in transforming our research, practices, and policies into a safer, more inclusive, and equitable field for all. In particular, we call for beginning with the following actions in research, practice, and policy arenas.

\section{Research Arenas-From Higher Education to Publishing}

- Advance long-term, antiracist, equitable frameworks, models, and theories to dismantle persistent inequities. Incorporate a diversity, equity, and inclusion (DEI) lens, with a focus on antiracism, into our research agendas with the goal of preventing and undoing racism. Currently the dominance of White perspectives and worldviews are continually perpetuated within the field while also disqualifying Black voices and

\footnotetext{
${ }^{1}$ Antiracism is defined as "The active process of identifying and eliminating racism by changing systems, organizational structures, policies and practices, and attitudes, so that power is redistributed and shared equitably" (NAC International Perspectives: Women \& Global Solidarity, n.d.).
}

Antiracist behavior is demonstrated by individuals, organizations, and systems when they become aware of the role of race and racism and how it affects Blacks, Indigenous, and people of color in society AND take action to identify, challenge, and change individual attitudes, organizations, policies, practices, and structures that produce and maintain inequalities.

Source: NAC International Perspectives: Women and Global Solidarity. (n.d.). Anti-Racism Defined. Retrieved from http://www.aclrc.com/antiracism-defined. 
experiences. By decolonizing our research efforts, youth development can begin to reject the marginalization of the intellectual interests of those who are traditionally underrepresented in the discipline and the profession. YD scholars must continue to scrutinize and dismantle White privilege within youth development, particularly resisting within-discipline exclusionary practices and rhetoric that position some scholars, subdisciplines, institutions, research areas, and so forth as worthier than others and thereby make racially restorative work more challenging. YD must embrace an inclusive crossdisciplinary approach, one that avoids reifying exclusionary boundaries and instead draws underrepresented scholars and those who work with underrepresented communities into conversations and takes seriously what they have to say, even when it departs from the taken-for-granted assumptions of the field of youth development.

- Expand research on race in youth development. More research is needed to explore how race intersects with other social categories and forms of social identification and grouping, particularly in ways that are not presented in a binary frame. Such work must also be triangulated with evidence deriving from rich, detailed social and cultural information, to ensure that speakers of languages and language varieties can express their own ideas about their own racial identities and that those ideas are represented in youth development research. Such an approach is especially important with those who do not fit easily within the closed set of racial categories often used in youth development research.

- Build antiracist research environments. The number of students and staff that are victims of racism in our higher education and research institutions is very problematic yet too often ignored. Overt and covert racial incidents are occurring, and though many are unreported, those that are reported are not dealt with actively or equitably. We have to begin asking the question of how policies and practices that are foundational to White normativity in science unduly influence our current knowledge base and our current research environmental practices.

- Commit to better understanding and dismantling systemic racism. Advocate for funding and dissemination of rigorous research that examines the impact of perceived and observed experiences of discrimination on youth developmental outcomes and the impact of policy changes and community-level interventions on reducing the effects of racism and other forms of discrimination on youth development

- Reexamine past and current research narratives. Some of the questions that need to and can guide future, fruitful research on issues related to race and youth development include 
- How are theories of race and previous work on race operationalized in youth development and youth development research?

- What methods or forms of analysis should scholars use to best capture the contemporary realities of how race and youth development intersect?

- What racial questions are currently being asked in youth development and does devaluation of certain questions lie along racial lines?

- How might youth development research itself, in its questions, methods, assumptions, and norms of dissemination, reproduce or work against racism?

- What existing racial theories (if any) are youth development scholars drawing from and which ones should scholars work to further include in order to advance our understanding of the impact of racism?

- What can youth development contribute to the understanding of race in other disciplines?

- What can youth development learn from other disciplines to contribute to youth development's understanding of race?

- How can people from underrepresented racial groups be empowered in youth development research?

- How does youth development research address power and contextual factors that maintain local, state and federal policies and practices that are discriminatory and perpetuate racial inequity and disparity?

- Recognize and address the extra burdens of scholars of color. Recognize that colleagues of color have for far too long been put in the unfair position of having to shoulder and take on the undue burden of work related to racism, inequities, bias, and bigotry in their institutions and in the field. This can no longer continue. Antiracism efforts and the transformation of our field cannot and must not lie only on the shoulders of scholars of color. It is our individual and collective responsibility as scholars to not only enhance our awareness of racism but also contribute to antiracism efforts.

- Include Black representation and voices to build a stronger and more representative field. In order to better serve our diverse communities of youth, scholars must intensify efforts to diversify a wide range of leadership roles and boards to better reflect and actively bring in the voices (adult and youth) of Blacks, Indigenous and immigrant communities. To fail to do so in the face of the growing diversity of the youth population in this country is not only short-sighted but unethical.

- Acknowledge our own biases. Acknowledge that we must confront our own internalized racism and implicit biases, and learn to think and act in ways that affirm and 
support our students, staff, faculty, and community members identifying as Black, African American, Native American, American Indian/Indigenous, Latinx, Asian American, Pacific Islander and all other racial and ethnic groups that are in the United States.

- Seek out, promote and be accountable for training on antiracism. Training of students, staff, and faculty on racism and its impact on our research methods, dissemination, funding, and institutional practices should be implemented.

- Actively develop a pipeline of diverse scholars. Dedicate resources and mentoring to establish and sustain a pipeline for entrance of diverse scholars into research and related leadership opportunities and professional promotion in youth development fields.

- Strengthen our field's journals' and other publications' understanding of racism and inclusion of antiracism efforts by

- Diversifying editorial boards. Seek out diversity in the publications committee and other editorial boards in publishing venues in order to increase the field's dedication in promoting diversity, inclusion, and opportunity in all aspects of journal functions and governance.

- Ensuring fairness in all journal processes and intolerance for noncollegial behavior of any kind. We know that reviewers carry biases regarding gender, race, and ethnicity when assessing manuscripts (Elsevier, 2017; Silbiger \& Stubler, 2019). There are also indications that there might be hidden biases in the submission process regarding other axes of diversity, such as sexual identity, disability, and socioeconomic status. Thus, journals and other publications should follow the example held by the Society for Research in Child Development (SRCD) policy on disclosure of sociocultural information and by the American Psychological Association (APA). Both have been designed to alleviate bias in the review process while also acknowledging diversity. JYD is forming a task force to review, replace, and revitalize our efforts in these areas.

- Celebrate racial scholarship and the commitment to racially and ethnically diverse communities. Highlight journal content that documents the impact of racism on youth development and make relevant articles free for all to read and share.

\section{Practice Arenas-From Professional Development to Program Practices}

- Provide antiracist training and educational resources. Identify, develop and distribute high quality training and educational resources for adult staff and volunteers 


\section{Race, Antiracism, and Youth Development}

on antiracism strategies recognizing implicit bias, increasing equity and active allyship. Educate youth workers about the negative ramifications of systemic racism and the benefits of diversity through targeted professional development activities. While there are resources available, support efforts to review and promote their wide use in the field. We encourage JYD to review resources in this area-particularly lists of resources already curated by reputable groups. This professional development should also include educating, engaging, and empowering youth, especially racially and ethnically diverse youth within their community, who are ready to become advocates as well. Finally, accountability through reporting systems, feedback loops and assessments (i.e., racial equity impact assessments) should be utilized.

- Encourage commitment to an antiracist agenda. Make learning about antiracism an expectation of employment in our field for all youth organization administrators and staff. These efforts should be informed by the population of youth they serve but not be limited by it nor present only in programs with racially and ethnically diverse youth. All people working with youth need to understand the nature and negative effects of racism of all types.

- Encourage policies to foster interactive learning communities that promote cultural humility. This includes such areas as self-awareness, lifelong commitment to self-evaluation, and commitment to managing power imbalances.

- Provide opportunities to ensure the workforce is competent to deliver culturally appropriate and youth-centered programs and services. Including support for the development of positive cultural identities, sociopolitical development, civic engagement, and social and emotional skills viewed through an equity lens.

- Advocate for development and use of diverse and antiracist curricula for and with youth. Curricula must be multicultural, multilingual, and reflective of the communities in which youth live as well as the diversity of the larger society of which they are a part. Regardless of the curriculum used, it should incorporate cultural diversity to ensure that there is a representation of authors, images, and stories that reflect the cultural diversity of youth served in youth development practice. This should include curriculum on social determinants of youth development, impact of racism on youth, and the history of racism in youth/adolescent development.

- Ensure all youth in our programs and practices have meaningful opportunities to discuss and come to understand racism, White privilege, prejudice, discrimination and institutional racism 
- Acknowledge the antiracist agenda within our professional associations. Readers are encouraged to explore statements and resources from both of the Journal of Youth Development's sponsoring organizations: The National Afterschool Association (NAA) and the National Association of Extension 4-H Youth Development Professionals (NAE4-HYDP) and related 4-H efforts. These include

- NAA Resources

- Black Lives Matter: A Statement to Members

- The Afterschool Leadership Landscape: Supporting and Strengthening Racial Equity - A 2020 Report

- Building the Capacity of Emerging Leaders of Color Initiative-Including information about the leaders selected

- NAE4-HYDP, 4-H and Other Extension Resources

- National 4-H Council statement and resources

- Resource list on extension for all of Extension

- Current resource list on social justice and equity

Policy Arenas-From Public Policy and Funding to Organizational Policies and Practices

- Personally and professionally acknowledge that youth equity is unachievable unless racism is addressed through a systemic approach.

- Policies and resources that shape and inform youth development practices should explicitly acknowledge racism and convey their commitment to all youth and their families.

- Public policy and funding, as well as private efforts, should work to create culturally safe youth organizations. Youth program and service providers funded need to acknowledge and demonstrate sensitivity to the racism that youth and their families experience by supporting the integration of culturally-based communication strategies and evidence-based tools and practices throughout the organization.

- Collaborate with diverse community-based organizations to eradicate policies and practices in youth development that are discriminatory and perpetuate racial injustice, inequity, and disparity.

- Convene leaders and collaborate with racially and ethnically diverse communities to develop a national standard and training in culturally competent care and programming. 
Race, Antiracism, and Youth Development

- Advocate for antiracism accountability at the institutional, state, and national level within our field and its respective organizations.

- Encourage and advance community-level advocacy with members of those communities disproportionately affected by racism to develop policies that advance social justice.

- Advocate for policies and actions that eliminate racism within our youth development/out-of-school-time system.

- Work to grow and invest both public and private resources to ensure equitable access to non-formal and informal community learning opportunities for all youth regardless of means, race, ethnicity, gender, sexual orientation, or ability.

- Ensure antiracism funding. Explore the creation of directed research and program grant programs dedicated to increasing equity and reducing racial disparities in youth development. Strive to partner only with sponsors who share a commitment to practices designed to eliminate racial disparities and increase equity in youth development.

- Advance policies and investments in research and practices that ensure evidence is generated, translated, and used to improve programs and practices that promote diversity, cultural respect, and antiracist practices.

\section{The Challenge}

Over the past few months each of us has tried to process the authentic and meaningful antiracist protests that have arisen across this nation and the world-too often accompanied by violence and overdone law-and-order responses. This commentary and call to action is but one part of what we challenge the field to do in the coming months as we build on and sustain this momentum for positive changes. As leaders in the field and members of the JYD Publications Committee we challenge each of our readers, reviewers, contributors, sponsors, and other leaders to not only educate themselves on antiracism and its associated issues but to also take an active stand against racism. In particular we challenge all of us to

- Write and submit articles that inform and elaborate on our understanding of these critical issues and their potential solutions.

- Work to elaborate, refine, debate, and act on some of the call to actions outlined above.

- Submit resources to JYD that advance these topics, either for the adult staff and their professional development or for direct use with youth in programs. We are working to 
identify authors and encourage both articles and the compilation and review of such resources in a coming issue of the journal.

- Support the work of an emerging JYD task force examining the policies and practices of the journal in order to make recommendations and changes that advance equity and racial justice-from composition of groups to review practices to the formation of alliances with other publications to innovative approaches to advance this work. Look for the task force's report later this coming spring.

In the end, the greatest challenge to each of us is to continue to use and build on the newfound, but long overdue momentum for fundamental changes around racial injustices in our society.

\section{Conclusions}

As members of the JYD publication committee, and on its behalf, we are working with JYD's editor, Kate Walker, section editors, and others to strive to do better and to bring more awareness to the biases in the youth development profession, and to help others understand the impact of racism. We also remain vigilant, acknowledging that hatred takes many forms and is often silent and opportunistic. We encourage the youth development field to recognize and celebrate the contributions that Black scholars have made to the field, and continue to make, despite the barriers that we have placed in front of them. The increase in overt racism and violence that is directed toward Black communities, and their Black youth, is one that has persisted for decades and must end if we truly believe in positive development of all children and youth. JYD understands that this must finally end, and we are committed to being a part of its ending through our antiracist efforts. Make no mistake, we are asking the field to center Blackness because of its long history of trauma, inequities and focus on Black/White binary research; however, we acknowledge that our approaches listed will assist al/ racially and ethnically diverse groups that have been systemically and disproportionately disadvantaged. JYD will deliberately use its platform to better inform scholars, youth workers, and the field by encouraging antiracist communications and policymaking that benefit allyouth.

JYD is committed to making a difference and we have begun the process of developing strategies for making our publications submission and selection processes as inclusive, accessible, and equitable as possible. Any effort, such as this commentary or the ongoing improvement of JYD is never complete. Notions of race and discussions about it are constantly 
Journal of Youth Development | http://jyd.pitt.edu/ | Vol. 15 Issue 5 DOI 10.5195/jyd.2020.1005 Race, Antiracism, and Youth Development

expanding, changing, and even in dispute. As this is a living statement, comments from readers of all academic and personal backgrounds are welcome and invited. They can be shared most readily with JYD through Facebook or Twitter (@JournalYouthDev) or directly with us as authors.

\section{Acknowledgement}

While the final views expressed in this commentary are those of the authors, we are grateful for the support and thoughts of many people who made this effort better. In particular, we wish to thank Kate Walker, Aerika Brittian Loyd, Nigel Gannon, Richard Lerner, Jill Young, Deb Moroney, Elijah Wilson, Beth Birnstihl, Nia Imani Fields, and Dorothy Freeman.

\section{References}

Adams-Wiggins, K. R., \& Taylor-García, D. V. (2020). The Manichean division in children's experience: Developmental psychology in an anti-Black world. Theory \& Psychology, 30(4), 485-506. https://doi.org/10.1177/0959354320940049

Bottrell, D. 2009. Understanding 'Marginal' perspectives: towards a social theory of resilience. Qualitative Social Work 8(3), 321-339. https://doi.org/10.1177/1473325009337840

Cammarota, J., \& Fine, M. (Eds.). (2010). Revolutionizing education: Youth participatory action research in motion. Routledge.

Deschenes, S., McLaughlin, M., \& Newman, A. (2008). Organizations advocating for youth: The local advantage. New Directions for Youth Development, 2008(117), 11-25.

https://doi.org/10.1002/yd.244

Elsevier (Amsterdam). (2017). Gender in the global research landscape: Analysis of research performance through a gender lens across 20 years, 12 geographies, and 27 subject areas. Author. https://www.elsevier.com/ data/assets/pdf file/0008/265661/ElsevierGenderReport final forweb.pdf

Foster, K. R., \& Spencer, D. (2011). At risk of what? Possibilities over probabilities in the study of young lives. Journal of Youth Studies, 14(1), 125-143. https://doi.org/10.1080/13676261.2010.506527

Gabriel, M. G., Brown, A., León, M., \& Outley, C. (2020). Power and Social Control of Youth during the COVID-19 Pandemic. Leisure Sciences, 1-7. https://doi.org/10.1080/01490400.2020.1774008

Gale, F., \& Bolzan, N. (2013). Social resilience: Challenging neo-colonial thinking and practices around 'risk.' Journal of Youth Studies, 16(2), 257-271. https://doi.org/10.1080/13676261.2012.704985 
Journal of Youth Development | http://jyd.pitt.edu/ | Vol. 15 Issue 5 DOI 10.5195/jyd.2020.1005 Race, Antiracism, and Youth Development

García Coll, C., Lamberty, G., Jenkins, R., McAdoo, H. P., Crnic, K., Wasik, B. H., \& García, H. (1996). An Integrative Model for the Study of Developmental Competencies in Minority Children. Child Development, 675), 1891-1914. https://doi.org/10.2307/1131600

Ginwright, S., \& Cammarota, J. (2002). New terrain in youth development: The promise of a social justice approach. Social justice, $29(4$ (90)), 82-95. http://www.jstor.org/stable/29768150

Killen, M., Rutland, A., \& Yip, T. (2016). Equity and justice in developmental science: Discrimination, social exclusion, and intergroup attitudes. Child Development, 875), 1317-1336. https://doi.org/10.1111/cdev.12593

Kirshner, B., \& Ginwright, S. (2012). Youth organizing as a developmental context for African American and Latino adolescents. Child Development Perspectives, 6(3), 288-294.

Marks, A. K., Ejesi, K., McCullough, M. B., \& García Coll, C. (2015). Developmental implications of discrimination. In M. E. Lamb \& R. M. Lerner (Eds.), Handbook of child psychology and developmental science ( $7^{\text {th }}$ ed., Vol. 3, pp. 324-365). Wiley. https://doi.org/10.1002/9781118963418.childpsy309

Outley, C., Brown, A., Gabriel, M. G., \& Sullins, A. (2018). The role of culture in out-of-school time settings. In P. Witt \& L. Caldwell (Eds.), Youth development principles and practices in out-ofschool-time settings (pp. 463-492). Sagamore Venture.

Pinckney, H. P., IV, Outley, C., Brown, A., \& Theriault, D. (2018). Playing while black. Leisure Sciences, 40(7), 675-685. https://doi.org/10.1080/01490400.2018.1534627

Silbiger, N. J., \& Stubler, A. D. (2019). Unprofessional peer reviews disproportionately harm underrepresented groups in STEM. PeerJ, 7, e8247. https://doi.org/10.7717/peerj.8247

Spencer, M. B., Dupree, D., \& Hartmann, T. (1997). A phenomenological variant of ecological systems theory (PVEST): A self-organization perspective in context. http://repository.upenn.edu/gse_pubs/4

Ungar, M. (2004). A constructionist discourse on resilience: Multiple contexts, multiple realities among atrisk children and youth. Youth \& Society 35(3), 341-365. https://doi.org/10.1177/0044118X03257030

Weiland, C., \& Yoshikawa, H. (2012). The effects of large-scale economic change and policies on children's developmental contexts and developmental outcomes. Child Development Perspectives, $6(4), 342-350$. 